\title{
The effect of nanocomposite packaging carbon nanotube base on organoleptic and fungal growth of Mazafati brand dates
}

\author{
Parinaz Asgari $\cdot$ Omid Moradi $\cdot$ Behjat Tajeddin
}

Received: 19 January 2014/ Accepted: 13 February 2014/Published online: 5 March 2014

(C) The Author(s) 2014. This article is published with open access at Springerlink.com

\begin{abstract}
In this work, nanocomposite low-density polyethylene films with carbon nanotube base were prepared by solution casting from boiling xylene. Fresh Mazafati dates were placed on the packages obtained from films and stored at ambient temperature. In addition, the fungal growth and sensory attributes were monitored on the 0th, 30th, 60th, and 90th days of storage. Although films containing carbon nanotube increased shelf life of Mazafati dates compared to controls, some of the characteristics of sensory were lost.
\end{abstract}

Keyword Carbon nanotube $\cdot$ Packaging Mazafati brand dates

\section{Introduction}

Over the past 200 years, packaging has become an important element for foods. Canned foods were invented in the time of Napoleon. In the Second World War, there was an increase in demand for packaged foods. Food and food packaging industry in the nineteenth century was developed significantly. An overview of developments in packaging, as follows:

\section{P. Asgari (ه)}

Department of Food Science and Technology, College of Agriculture, Shahr-e- Qods Branch, Islamic Azad University, Tehran, Iran

e-mail: asgari.parinaz@yahoo.com

O. Moradi

Department of Chemistry, College of Science, Shahr-e- Qods Branch, Islamic Azad University, Tehran, Iran

B. Tajeddin

Department of Food Science and Technology, Agricultural Engineering and Research Institute, Karaj, Iran 1800-1850s: Food pasteurization uses heat, and canning the food both lead to increase shelf life. In 1890s, the idea of fully automatically producing bottles was raised. In 1939: ethylene was commercially polymerized for the first time. Since 1960, Polyethylene is widely used for food packaging. In 1970, polyethylene terephthalate were used for packaging carbohydrate drinks and cola. In 2006, Nanotechnology has created revolution in the packaging industry [1].

Often food product can canker by moisture, oxygen, light and heat. The purpose of packaging is to preserve food against spoilage (chemical, biological, physical and microbiological) and also to increase shelf life; thus, transportation is better and easier. In addition to packaging's ability to protect the product, the relative information about the product could also be transferred to the consumer, including storage conditions, usage instruction and nutritional value of the product, etc. So, food packaging is important in the food industry. Materials of food packaging are different, including paper, glass, metal and plastic [2]. Plastic polymers are hydrocarbon compounds that were obtained from basic hydrocarbon as an example ethane and methane, they are derived from natural gas and petroleum [3]. Some polymeric film materials which are commonly used in packaging food products include [2] polyethylene (PE, polythene): commonly, which are divided into two categories: [2] highdensity polyethylene (HDPL), low-density polyethylene (LDPE), [3] poly (vinyl chloride) (PVC), [4] polypropylene (PP), [5] poly (vinylidene chloride) (PVdC), etc. [3].

Some of packaging containers are in direct contact with food, so their use depends on the approval by the food and drug administration (FDA) [3].

Food packaging increases the shelf life of products, moreover, costs of storage, transportation, and amount of the waste are reduced. Packaging is also important for 
some foods such as dates. As date is one of the most important products of Iran, it plays a main role in people's nutrition and the exports of this product are also of importance. Thus, we must provide effective solutions for storing this product so as to compete with other exporting countries $[4,5]$. On the other hand, Mazafati dates tissue is soft and has a high moisture content of approximately 20-40\%; therefore, microorganisms are able to grow on it and so they can convert sugar into Lactic acid. Due to nonhealthy and non-scientific improper packaging, about $35 \%$ of the dates are converted to waste. The purpose of this research is to introduce an appropriate packaging solution for dates, considering economical values.

One of the most important factors in food marketing is the fact of presenting the product to the market. The packaging of a product is the first thing that catches the consumer's eyes [5]. On the other hand, the food packaging industry is an important industry. It is a protective means which is applied to keep the products fresh and healthy (in the phase of post-harvest) until consumption [6].

As mentioned before, the role of packaging is to preserve the food, by adding regenerator agents or adding composite to improve the film properties. To maintain quality, reduce waste and increase efficiency, different fields of science such as nanotechnology are considered [7-9]. Recently, nanotechnology has been used in the food packaging industry which can be effective on some attributes, for example, it can increase food shelf life and improve it [9]. Nanotechnology means any technology on a nanoscale [10]. Nanotechnology will be another revolution in the industry [10].

In 1991, lijima [11] discovered carbon nanotubes (CNTs). One of the carbon nanotube applications is using them as nanocomposite materials [12]. Nanotubes are divided into two categories: single-walled (SWNT) and multi-walled (MWNT); and CNTs are classified into three groups on some articles, such as SWNTs (single-walled carbon nanotubes) $[13,14]$, DWNTs (double-walled carbon nanotubes) [15], and MWNTs (multi-walled carbon nanotubes) [16]. All nanotubes have shown high tensile strength [8, 17], and excellent mechanical properties [16], therefore, carbon nanotubes can also be used as polymer's reinforcing agents; CNTs can be used as a filler for polymer nanocomposites [15].

\section{The experiments}

Preparation of antimicrobial nanocomposite films

The polyethylene granules (LDPE; melt flow index 2 $\mathrm{g} / 10 \mathrm{~min}$, density $0.92 \mathrm{~g} / \mathrm{ml}$ ) and carbon nanotubes (purity $>99 \mathrm{wt} \%$ ) were prepared by solution casting from boiling xylene (Merck), at $100{ }^{\circ} \mathrm{C}$ for an hour. Particles of carbon nanotubes, at three different levels $(0.3,0.1$ and $0.001 \% ; \mathrm{C} 1$, $\mathrm{C} 2$ and $\mathrm{C} 3$, respectively) were added to $10 \mathrm{ml}$ of xylene. Then, the ultrasonic (30 min) and homogeniser (30 min) became uniform; the solution is then added to the transparent solution of xylene and polyethylene. It was homogenized again when the solution was poured and the film was cast in Pyrex dish. The Solution was stored for $24 \mathrm{~h}$ at room temperature, until the solvent evaporated and then stored for an additional $24 \mathrm{~h}$ at $90{ }^{\circ} \mathrm{C}$ inside a vacuum oven to dry. Films that were left in distilled water for about $1-2 \mathrm{~h}$ were placed in a desiccator later [18]. The control samples were produced by the same method (casting of LDPE in xylene).

Film thickness using a micrometer at five different points of the film is measured and reported.

Mazafati brand dates packaging and storage

Mazafati dates were purchased from market in Tehran, Iran, and were packed within the films prepared under sterile conditions and stored at ambient temperature. The microbial and sensory characteristics of samples evaluated on $0,30,60$ and 90 days of storage.

Microbial analysis

The powder of medium was mixed with 11 of distilled water and the transparent medium was sterilized in $121{ }^{\circ} \mathrm{C}$ and then added to the plate. Incubation was performed at $25^{\circ} \mathrm{C}$ for 5 days. Total yeast and mold were counted using the surface plate method and reported as CFU (colony forming units) per milliliter (ISIRI 10899-2) [19].

\section{Sensory evaluation}

Sensory properties of the Mazafati brand dates such as texture, odor and public acceptance were evaluated [20]. The evaluation scheme uses 1 for "very poor" and 5 for "excellent" [21].

\section{FTIR analysis}

The equipment used for this research, PerkinElmer spectrometer, is a FTIR spectrometer. The bands were selected for the analysis of polyethylene and carbon nanotube in the $450-4,000 \mathrm{~cm}^{-1}$ range. The results were obtained from comparing the ratio of the height of samples containing carbon nanotubes absorbance peak with the control.

Statistical analysis

Analysis of variance based on a completely randomized design was performed using SPSS (v 20) software. The results were analyzed by ANOVA (one-way variance 
analysis). $P$ values of $<0.05$ indicate statistically significant differences.

\section{Results and discussion}

Fungal quality

The number of yeasts and molds at ambient temperature during 90 days of storage is shown in Fig. 1. The results showed that the existing samples containing carbon nanotube film on antimicrobials are more effective than pure polyethylene film. During 90 days of storage, the control sample showed an increase of 0.12 cycles logarithmic in molds and yeasts while samples containing carbon nanotube 0.82 cycles logarithmic shown decrease. It was reported that the nanotubes are antibacterial properties. Nanotube concentration was lethal to Escherichia coli, which probably caused perforation of microbial cells and irreversible damages [22]. It can be observed that nanocomposite fungal growth is effective, which is in agreement with the findings of Emamifar et al. [9] and Sattari Najaf Abadi et al. [23] for similar nanofilms.

The results showed that the number of microorganisms in the control group was increased, while it was not in nanofilms. According to the analysis of variance (Table 1), the difference was statistically significant. It seems that the initial microbial load and moisture were affected by the fungal growth in storage time. It seems that the antimicrobial effect is enhanced due to the uniform distribution of carbon nanotubes and lack of agglomeration of CNT, (according to the electron microscopy images; Figs. 2, 3).

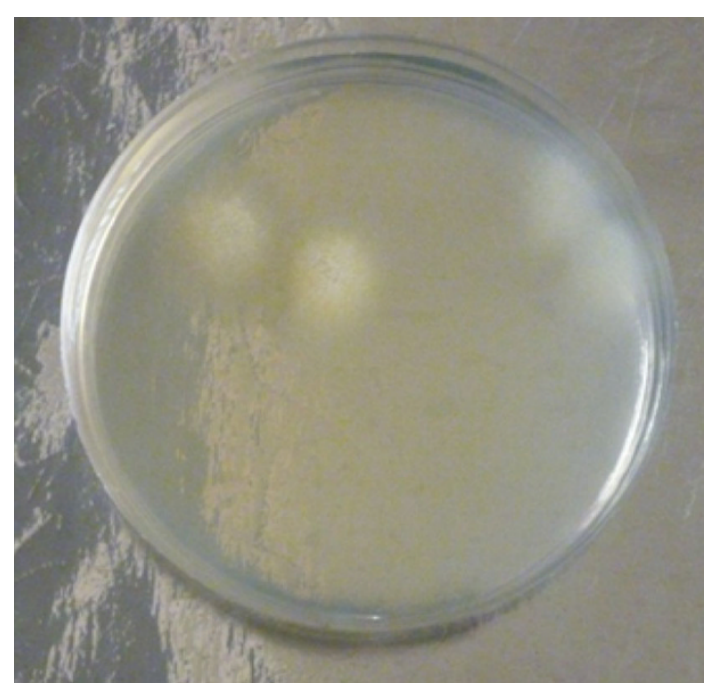

Fig. 1 Growth of molds and yeasts at the storage time for Mazafati brand dates
Table 1 Analysis of variance for molds and yeasts

\begin{tabular}{lrrrr}
\hline Source & $\begin{array}{l}\text { Type III sum of } \\
\text { squares }\end{array}$ & $d f$ & Mean square & \multicolumn{1}{l}{$F$} \\
\hline $\mathrm{T} *$ Day & $5,523,520.545$ & 63 & $87,674.929$ & 100.248 \\
$\mathrm{~T}$ & $14,174,460.091$ & 21 & $674,974.290$ & 771.767 \\
Day & $61,184,586.455$ & 3 & $20,394,862.152$ & $23,319.518$ \\
Error & $153,926.667$ & 176 & 874.583 & \\
Total & $207,019,624.000$ & 264 & & \\
\hline
\end{tabular}

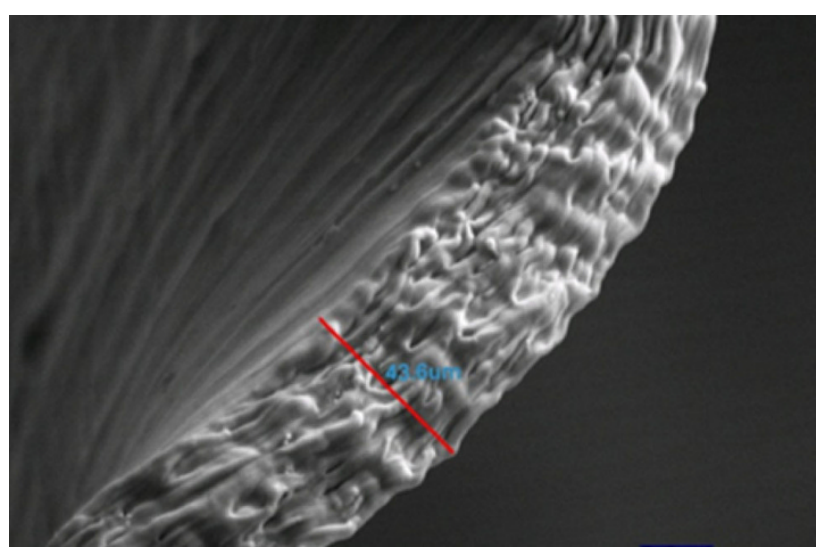

Fig. 2 SEM antimicrobial carbon nanotube films

It seems that with an increase in concentration of carbon nanotube, the antimicrobial properties were increased, which agrees with the findings of costa [19] for similar nanofilms.

\section{Sensorial quality}

Sensory evaluations were performed by non-parametric methods on ten participants, with samples of Mazafati brand dates having different coatings. The scores given by the evaluators, for all samples on days 0,30 and 60, showed no significant differences among the samples; while the parameters of flavor and general acceptability were statistically significant. These results agree with the findings of Emamifar et al. [9] and Sattari Najaf Abadi et al. [23], for a similar nanofilms.

\section{FTIR analysis}

The spectra of the two samples of film are shown in Figs. 4 and 5. According to the figures, it is noted that all presented the same absorption, varying only in terms of intensity, which can be related to differences in film compound. Figure 4 shows the FTIR spectrum of pure polyethylene and Fig. 5 shows the FTIR spectrum of nanocomposite 


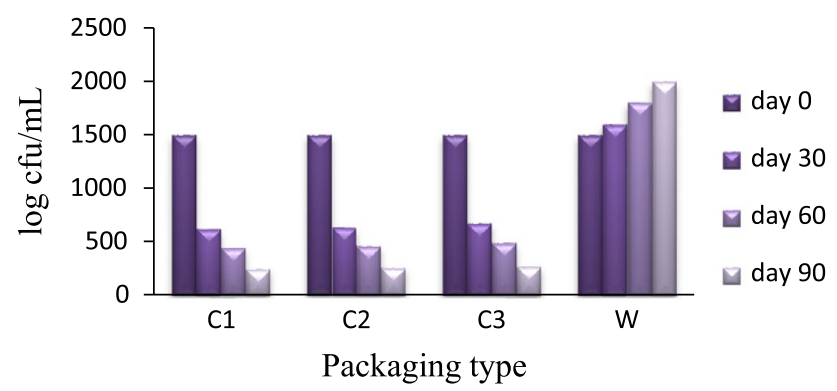

Fig. 3 Growth of molds and yeasts at the storage time for Mazafati brand dates

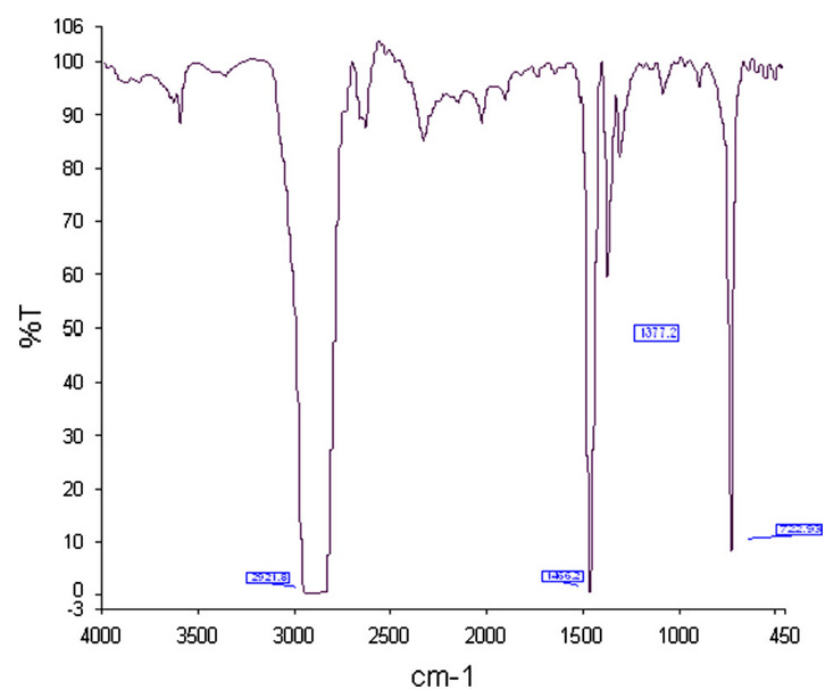

Fig. 4 FTIR spectra of pure polyethylene (PE)

packaging containing carbon nanotubes. FTIR analysis revealed that the $=\mathrm{C}-\mathrm{H}$ (flexural) at $690-900 \mathrm{~cm}^{-1}, \mathrm{C}=\mathrm{C}$ (vibratory) at $1,475-1,600 \mathrm{~cm}^{-1}$ and $\mathrm{C}-\mathrm{H}$ (vibratory) at $3,000 \mathrm{~cm}^{-1}$ were observed.

\section{Conclusions}

In this research, the effect of different concentrations of carbon nanotubes on organoleptic properties and fungal growth of Mazafati brand dates was studied. The purpose of this study was to evaluate the sensory characteristics and microbial films on Mazafati date during the storage. It was shown that uniform dispersion of carbon nanotubes in the polymer networks can have an effect on the antimicrobial activity of this packaging.

Results suggested that nanopackaging increases shelf life of Mazafati brand dates, while that part of sensory attributes was lost. It can be concluded that nanofilm decreases the fungal growth.

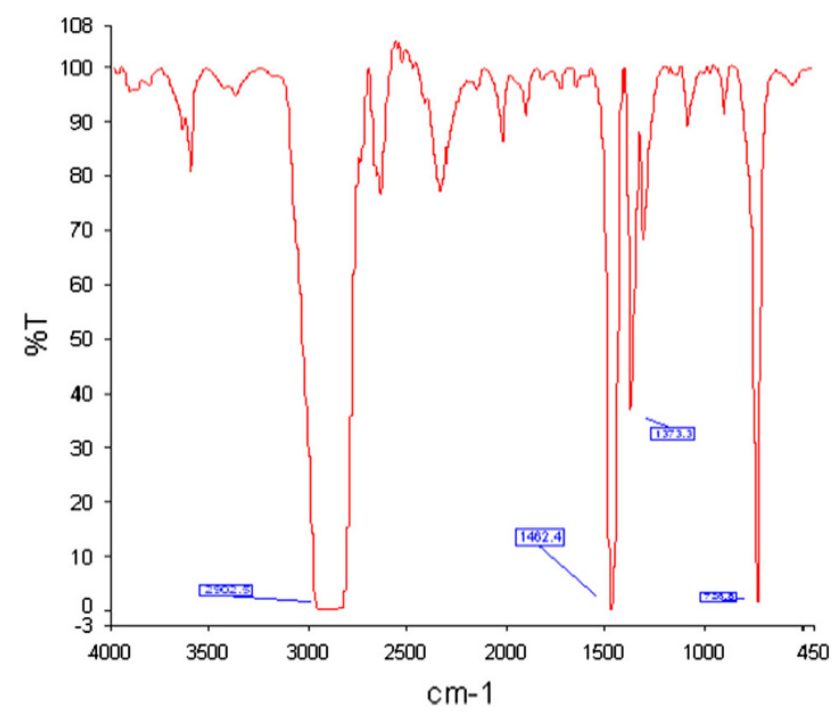

Fig. 5 FTIR spectra of nanocomposite packaging containing carbon nanotubes

Open Access This article is distributed under the terms of the Creative Commons Attribution License which permits any use, distribution, and reproduction in any medium, provided the original author(s) and the source are credited.

\section{References}

1. Coles, R., Kirwan, M.: Food and Beverage Packaging Technology, Second edn. (2011)

2. Vaclavic, V.A., Christian, E.W.: Essentials of food science, 3rd edn. Springer, New York (2008)

3. Ahmed, A.: Funct. Polym. Mater. Agric. Food Ind. (2013). doi:10.1007/978-1-4614-7061-8_6

4. Ashrafjahani, A.: Dates Fruit of Life. Publishing Agricultural Sciences (2002)

5. Saraei, J.: Dates and curing process-producing ancillary products. Publications Barsava (1996)

6. Mirnezamiziabari, S.H.: Principles of food packaging, 6th print. Publication of Aeizh (2010)

7. Abdollahi, M., Rezaei, M., Ferzi, G.A.: Preparation and evaluation of biodegradable nanocomposite properties of chitosan/ nanoclay for use in food packaging. Res. J. Food Sci. Technol 7(1), 71-79 (2011)

8. Azeredo, H.: Nano-composites for food packaging applications. Food Res. Int 42, 1240-1253 (2009)

9. Emamifar, A., Kadivar, M., Soleimanianazd, S., Shahedi, M.: Evaluation of nano-composite packaging containing $\mathrm{Ag}$ and $\mathrm{ZnO}$ on shelf life of fresh orange juice. Innovative Food Sci. Emerg. Technol 11, 742-748 (2010)

10. Bhushan, B.: Handbook of Nanotechnology, 3rd edn. Springer, New York (2010)

11. Lijima, S.: Helical microtubules of graphitic carbon. Nature 354, 56-58 (1991)

12. Xie, X.-L., Mai, Y.-W., Zhou, X.-P.: Dispersion and alignment of carbon nanotubes in polymer matrix: a review. Mater. Sci. Eng. R. Rep. 49:89-112 (2005). http://www.scribd.com/doc/9982 6599/Dispersion-and-Alignment-of-Carbon-Nanotubes-in-PolymerMatrix-a-Review

13. Lijima, S., Ichichashi, T.: Single-shell carbon nanotubes of 1-nm diameter. Nature 363, 603-605 (1993) 
14. Bethune, D.S., Kiang, C.H., Devries, M.S.: Cobalt-catalyzed growth of carbon nanotubes with single-atomic-layer walls. Nature 363, 605-607 (1993)

15. Bandow, S., Takizawa, M., Hirahara, K.: Raman scattering study of double-wall carbon nanotubes derived from the chains of fullerenes in single-wall carbon nanotubes. Chem. Phys. Lett 337, 48-54 (2001)

16. Sahoo, N., Ranab, S., Cho, J., Li, L., Chan, S.: Polymer nanocomposites based on functionalized carbon nanotubes. Prog. Polym. Sci 35(7), 837-867 (2010). (ISSN 0079-6700)

17. Lau, K.T., Hui, D.: The revolutionary creation of new advanced materials carbon nanotube composites. Compos. B 33(4), 263-277 (2002)

18. Gregorova, A., Redik, S., Sedlarik, V., Stelzer, F.: Lignin-containing polyethylene films with antibacterial activity. In: NANOCON 2011, 21-23 September 2011, pp. 1-6. Brno, Czech Republic (2011)
19. Institute of Standards and Industrial Research of Iran, ISIRI: Microbiology of food and animal feeding stuffs : horizontal method for the enumeration of yeasts and moulds. Part 1 : Colony count technique in products with water activity less than 0.95 , ISIRI no 10899-2. 1st edn. Karaj (2008)

20. Costa, C., et al.: Antimicrobial Silver-montmorillonite nanoparticles to prolong the shelf life of fresh fruit salad. Int. J. Food Microbiol 148, 164-167 (2011)

21. Lucera, A.: Influence of different packaging systems on fresh-cut zucchini (cucurbitapepo). Innovative Food Sci. Emerg. Technol 11, 361-368 (2010)

22. Kang, S., Pinault, M., Pfefferle, L.D., Elimelech, M.: Singlewalled carbon nanotubes exhibit strong antimicrobial activity. Langmuir 23, 8670-8673 (2007)

23. Sattarinajafabadi, M., Minaei, S., Azizi, M.H., Afshari, H.: Effect of packaging with nano films on organoleptic and microbial properties. Iran. Food Sci. Nutr 4, 65-74 (2009) 